\title{
Risks of respiratory disease in the heavy clay industry
}

R G Love, E R Waclawski, W M Maclaren, G Z Wetherill, S K Groat, R H Porteous, C A Soutar

Institute of

Occupational

Medicine, Edinburgh

R G Love

E R Waclawski

W M Maclaren

G Z Wetherill

$S$ K Groat

R H Porteous, deceased

C A Soutar

Correspondence to:

Dr R Love, Institute of

Occupational Medicine, 8

Roxburgh Place, Edinburgh

EH8 9SU, Scotland, UK

Accepted 17 September 1998
Abstract

Objectives-Little information is available on the quantitative risks of respiratory disease from quartz in airborne dust in the heavy clay industry. Available evidence suggested that these risks might be low, possibly because of the presence in the dust of other minerals, such as illite and kaolinite, which may reduce the harmful effects of quartz. The aims of the present cross sectional study were to determine among workers in the industry (a) their current and cumulative exposures to respirable mixed dust and quartz; (b) the frequencies of chest radiographic abnormalities and respiratory symptoms; (c) the relations between cumulative exposure to respirable dust and quartz, and risks of radiographic abnormality and respiratory symptoms.

Methods-Factories were chosen where the type of process had changed as little as possible during recent decades. 18 were selected in England and Scotland, ranging in size from 35 to 582 employees, representing all the main types of raw material, end product, kilns, and processes in the manufacture of bricks, pipes, and tiles but excluding refractory products. Weights of respirable dust and quartz in more than 1400 personal dust samples, and site histories, were used to derive occupational groups characterised by their levels of exposure to dust and quartz. Full size chest radiographs, respiratory symptoms, smoking, and occupational history questionnaires were administered to current workers at each factory. Exposureresponse relations were examined for radiographic abnormalities (dust and quartz) and respiratory symptoms (dust only).

Results-Respirable dust and quartz concentrations ranged from means of 0.4 and $0.04 \mathrm{mg} \cdot \mathrm{m}^{-3}$ for non-process workers to 10.0 and $0.62 \mathrm{mg} \cdot \mathrm{m}^{-3}$ for kiln demolition workers respectively. Although $97 \%$ of all quartz concentrations were below the maximum exposure limit of $0.4 \mathrm{mg} \cdot \mathrm{m}^{-3}$, $10 \%$ were greater than this among the groups of workers exposed to most dust. Cumulative exposure calculations for dust and quartz took account of changes of occupational group, factory, and kiln type at study and non-study sites. Because of the importance of changes of kiln type additional weighting factors were applied to concentrations of dust and quartz dur- ing previous employment at factories that used certain types of kiln. 85\% (1934 employees) of the identified workforce attended the medical surveys. The frequency of small opacities in the chest radiograph, category $\geqslant 1 / 0$, was $1.4 \%$ (median reading) and seven of these 25 men had category $\geqslant 2 / 1$. Chronic bronchitis was reported by $14.2 \%$ of the workforce and breathlessness, when walking with someone of their own age, by $4.4 \%$. Risks of having category $\geqslant 0 / 1$ small opacities differed by site and were also influenced by age, smoking, and lifetime cumulative exposure to respirable dust and quartz. Although exposures to dust and to quartz were highly correlated, the evidence suggested that radiological abnormality was associated with quartz rather than dust. $A$ doubling of cumulative quartz exposure increased the risk of having category $\geqslant 0 / 1$ by a factor of 1.33 . Both chronic bronchitis and breathlessness were significantly related to dust exposure.

Conclusions-Although most quartz concentrations at the time of this study were currently below regulatory limits in the heavy clay industry, high exposures regularly occurred in specific processes and occasionally among most occupational groups. However, there are small risks of pneumoconiosis and respiratory symptoms in the industry, although frequency of pneumoconiosis is low in comparison to other quartz exposed workers.

(Occup Environ Med 1999;56:124-133)

Keywords: respiratory disease; chest radiography; heavy clay industry; respirable dust and quartz; cumulative exposure

There is a continuing international debate on recommended occupational exposure limits for respirable quartz. In the United States the American Conference of Governmental Industrial Hygienists (ACGIH) has recommended a $0.1 \mathrm{mg} \cdot \mathrm{m}^{-3}$ average concentration per shift. ${ }^{1}$ The maximum exposure limit (MEL) in the United Kingdom is $0.4 \mathrm{mg} . \mathrm{m}^{-3}$, a value which should not in any circumstances be exceeded. ${ }^{2}$ A World Health Organisation working party suggested a health based exposure limit of 0.04 $\mathrm{mg} \cdot \mathrm{m}^{-3}$ but recommended further research into the risks related to exposure to airborne quartz. ${ }^{3}$ The risks associated with exposure to quartz are thought to vary from industry to industry and the presence of other minerals in the dust may lessen the harmful effects of 
quartz, ${ }^{4}$ particularly when it is associated with clay minerals, such as illite, kaolinite, and smectite, as in the heavy clay industry.

The heavy clay industry manufactures bricks, pipes, and tiles for general and special construction purposes. Refractory products are also made but these processes have not been included in this study. Previous investigations of dust conditions in the industry have been made in Canada, ${ }^{5}$ the United States, ${ }^{67}$ the United Kingdom, ${ }^{8}$ and more recently in South Africa. ${ }^{9}$ Dust concentrations have exceeded relevant control limits in some instances. ${ }^{5}$

Studies of the health effects of exposure to dust in the heavy clay industry have also been carried out in Europe, North America, and South Africa during the past 60 years. Sayers et $a l^{10}$ found no serious health risk in the United States industry, and limited evidence of respiratory disease, including silicosis, is apparent from several other studies. ${ }^{56811}$ Five per cent of brickmakers were reported to have abnormal chest radiographs in North Carolina $^{12}$ and in South Africa Sluis-Cremer ${ }^{13}$ quoted an incidence of 23 cases of silicosis per 1000 brick workers. In a recent cross sectional study of South African brickworks there was a prevalence of pneumoconiosis (category $\geqslant 1 / 0$ ) of $4 \%$, which increased with cumulative exposure to respirable dust and years of service in the brickmaking industry. ${ }^{14}$

The National Federation of Clay Industries (NFCI, now the British Ceramics Confederation) commissioned this cross sectional study, the aims of which were: to identify the current exposures to respirable mixed dust and quartz among those working on a range of typical processes in the United Kingdom heavy clay industry; to estimate cumulative exposures to dust and quartz; to determine the frequency of respiratory symptoms and radiographic abnormalities in these workers; and to investigate the relations between cumulative exposures and risks of respiratory disease.

\section{Methods}

After an initial on site assessment 18 brick and tile works were selected to take account of a range of conditions in the industry. Raw materials, end product, type of process, numbers employed, and geographical location were taken into account. A study population of about 2000 employees was planned, drawn from works ranging in size from 30 to 500 employees.

The selected plants included one large soft clay works with traditional Hoffman (moving fire) kilns, two medium sized soft clay works, one medium sized works using marl, two small works using the soft mud process, a hand made tile works, and 11 small to medium plants using harder shale based clays producing a range of product types. Works were also selected on the basis that some or all of the production processes had not changed substantially during the previous 20 years, thus enabling more reliable, although approximate, estimates of cumulative exposures to dust and quartz to be derived. Occupational hygiene and medical surveys were carried out at these sites during 1990-1.

\section{OCCUPATIONAL HYGIENE SURVEYS}

Occupational hygienists visited the sites and compiled detailed site histories, including such information as the age of the plant $(20->100$ years), changes in type of kiln and fuel, changes in setting and packing procedures-for example, automation - use of sand - for example, as facing material - changes in machinery, and use of local exhaust ventilation and respiratory protective equipment. Over 300 different jobs were identified, and were combined into 23 groups on the basis of location, activity, and likely exposure level. A sampling strategy was devised to measure the typical concentrations of repirable dust and crystalline silica in these sampling groups, based on personal sampling supplemented by several static samples to evaluate concentrations in areas where people passed through but did not carry out specific tasks.

The sampling surveys, with an agreed protocol and standard methods, ${ }^{15}$ took 5 days at most sites, and 10 days for larger sites. Employees carried personal dust samplers (Casella cyclone), which supplied a total of 1465 personal airborne dust samples. Of these 1407 were available for dust analysis (33-245 for each site, depending on size and nature of work) and 1403 were analysed for crystalline silica content. Respirable dust weights were calculated $^{15}$ and converted to airborne concentrations. Quartz content was derived by infrared spectrophotometry, ${ }^{16}$ or in some cases by the direct method of $x$ ray diffraction, ${ }^{17}$ or by the potassium bromide disc method of infrared spectroscopy. ${ }^{18}$

\section{MEDICAL SURVEYS}

All current employees were invited to attend a medical survey at the factory, except drivers of delivery vehicles transporting products off site. A full size chest radiograph was taken in a mobile $x$ ray unit with a standard method. ${ }^{19}$

A questionnaire of respiratory symptoms (based on the MRC questionnaire ${ }^{20}$ with supplementary questions about asthmatic symptoms) and smoking habits was administered by trained personnel. Details of all jobs since leaving school were recorded, including job title, nature of employer's business, periods of unemployment, and military service. Occupations in the heavy clay industry were recorded compatibly with the occupational groups identified during occupational hygiene surveys, and used as the basis for the sampling design. Jobs external to the heavy clay industry were classified as either noxious or nonnoxious according to the expert judgement of an occupational hygienist on likelihood of exposure to hazardous airborne agents.

After assessment for routine clinical purposes, all the chest radiographs were randomised and classified independently by three physicians experienced in the use and interpretation of the appearances of pneumoconiosis according to the International Labour Organisation (ILO) classification. ${ }^{19}$ 
A planned survey of ex-workers at two factories was discontinued because of a poor response to the invitations.

STATISTICAL ANALYSES

The measured dust concentrations and their estimated quartz components were analysed to identify important sources of systematic variation. Analysis of variance (ANOVA) models were fitted to the logarithms of the concentrations, to examine the contributions of occupational group, site (distinguished by kiln type), variations between sampling days, and interactions between these factors. The analyses took account of the fact that the replication of these factors in the data set was unbalanced.

The output of the ANOVAs was a set of estimated geometric mean dust and quartz concentrations retaining only the principal sources of variation. Past concentrations for these occupational groups were estimated from these means by noting the dates of changes in kiln type at a site (table 1) and scaling appropriately. Concentrations experienced during work at other heavy clay factories were estimated as the means, for each occupational group, of the concentrations at all sites sharing the same kiln type. Where necessary, changes in kiln type were inferred by date.

Three different indices of cumulative exposure to respirable dust and to respirable quartz were estimated for individual workers, by summing over the periods of employment in different occupational groups. Simple cumulative exposure was calculated by summing, over all periods, the product of the duration of the period and the appropriate geometric mean concentration. The two alternative indices involved weighting each product, before summation, by the time elapsed between the period and the date of survey, or by the square root of the time elapsed. These exposure indices were designed to be appropriate to dosimetry models where the exposure has a sustained effect on risk, perhaps through persisting in the lung and resisting clearance.

Time spent working outside the heavy clay industry was accumulated into eight classes to take account of dusty or otherwise noxious activities.

Indices of profusion of small opacities and the size of large opacities were defined as the median of the three readers' classifications: profusion being treated as having 12 values $(0 /-$ to $3 /+$ ) and large opacities as having four values

Table 1 Dates of changes in kiln types at 18 study sites (changes assumed to occur in the middle of the year)

\begin{tabular}{|c|c|c|c|}
\hline \multirow[b]{2}{*}{ Site } & \multicolumn{3}{|l|}{ Kiln type } \\
\hline & $\begin{array}{l}\text { Hoffman or } \\
\text { intermittent }\end{array}$ & Both & Tunnel \\
\hline $1-4$, and $12-17$ & \multicolumn{3}{|c|}{ No change (always Hoffman or intermittent) } \\
\hline 5 & $<1965$ & $1965-68$ & $>1968$ \\
\hline 6 & $<1969$ & No transition & $>1969$ \\
\hline 7 & $<1972$ & No transition & $>1972$ \\
\hline 8 & $<1974$ & No transition & $>1974$ \\
\hline 9 & $<1978$ & No transition & $>1978$ \\
\hline 10 & $<1965$ & No transition & $>1965$ \\
\hline 11 & $<1966$ & No transition & $>1966$ \\
\hline 18 & $<1965$ & $1965-80$ & $>1980$ \\
\hline
\end{tabular}

(O, A, B, and C). Frequency distributions were derived and cross tabulation was used to examine repeatability of each reader's classifications and agreement between readers. Prevalences of chronic bronchitis and breathlessness were expressed as percentages by age, smoking habit, and site.

Exposure-response relations for dust and quartz were examined by multiple logistic regression analysis for radiological abnormality (category $\geqslant 0 / 1$ and category $\geqslant 1 / 0$ ). Goodness of fit of regression equations was examined according to the method of Hosmer and Lemeshow. ${ }^{21}$ Analysis of respiratory symptoms was carried out similarly but only for exposure to dust, not quartz. Other explanatory variables studied included age, smoking habit, work site, and time spent in other industries.

\section{Results}

RESPONSE AND PARTICIPATION

All but two of the selected factories agreed to participate in the study. Reasons for withdrawal included recent large scale redundancies. Two additional stock brick works were recruited, resulting in a total of 18 factories operated by 10 different companies.

Medical surveys were attended by 1934 current employees. Taking into account those who had left before the surveys began the response rate for survey attendance was $85.2 \%$. Subsequently, another nine people were excluded from the final study population for not fulfilling the criteria for employees based at the selected sites.

AIRBORNE CONCENTRATIONS OF RESPIRABLE DUST AND QUARTZ

The occupational hygiene surveys collected 1465 personal airborne dust samples. After rejection of unsuitable samples, 1407 gave estimates of airborne dust concentration, and 1403 of these estimates gave the percentage of quartz in the sampled dust. Between 33 and 245 valid samples were available for each site.

The sampling effort covered 23 sampling groups. After examination of the measured dust concentrations, and with knowledge of the nature of the industry, these were combined into 12 occupational groups. Table 2 summarises the distributions of the dust concentrations and the quartz concentrations derived for each of these occupational groups, pooled over sites.

Quartz was detected and measured in $97 \%$ of dust samples and its concentration ranged from 0.01 to $3.8 \mathrm{mg} \cdot \mathrm{m}^{-3}$. The average quartz concentration for each occupational group ranged from $0.04 \mathrm{mg} \cdot \mathrm{m}^{-3}$ for those with no direct exposure to $0.62 \mathrm{mg} \cdot \mathrm{m}^{-3}$ for kiln demolition workers. The highest individual concentrations were experienced by general labourers and factory cleaners. Quartz concentrations were generally similar in all types of works but pan mill workers who used shale were exposed to concentrations $\left(0.23 \mathrm{mg} \cdot \mathrm{m}^{-3}\right)$ more than twice those $\left(0.09 \mathrm{mg} \cdot \mathrm{m}^{-3}\right)$ at soft clay and marl based works. Although most $(97 \%)$ quartz concentrations were below $0.4 \mathrm{mg} \cdot \mathrm{m}^{-3}$, the current MEL in the United Kingdom, over $10 \%$ of concentrations were greater than the MEL 
Table 2 Airborne concentrations of respirable dust and quartz (mg. $\left.m^{-3}\right)$ by occupational group

\begin{tabular}{|c|c|c|c|c|c|c|c|c|}
\hline \multicolumn{2}{|c|}{ Occupational group } & \multirow[b]{2}{*}{ Samples $n$} & \multicolumn{3}{|c|}{ Mean dust concentration } & \multicolumn{3}{|c|}{ Mean quartz concentration } \\
\hline No & Name & & All & Min & Max & All & Min & Max \\
\hline 1 & Office, canteen & 18 & 0.4 & 0.3 & 1.3 & 0.04 & 0.02 & 0.13 \\
\hline 2 & Supervisors & 336 & 0.6 & 0.3 & 1.6 & 0.05 & 0.02 & 0.18 \\
\hline 3 & Preproduction (quarries, moulders) & 301 & 1.0 & 0.4 & 1.6 & 0.11 & 0.04 & 0.28 \\
\hline 4 & Brick cutters & 10 & 1.0 & 0.3 & 1.4 & 0.12 & 0.04 & 0.21 \\
\hline 5 & Mixed (fitters, fork lift truck drivers) & 164 & 1.2 & 0.4 & 5.9 & 0.07 & 0.02 & 0.15 \\
\hline 6 & Postproduction (packers, kiln bricklayers) & 202 & 1.5 & 0.3 & 2.3 & 0.11 & 0.02 & 0.21 \\
\hline 7 & Fork lift drivers in kilns or driers & 46 & 1.6 & 0.3 & 2.4 & 0.13 & 0.04 & 0.22 \\
\hline 8 & Pan mill operators & 83 & 1.7 & 0.4 & 5.8 & 0.18 & 0.04 & 0.75 \\
\hline 9 & Labourers & 172 & 1.7 & 0.3 & 4.8 & 0.15 & 0.03 & 0.38 \\
\hline 10 & Sand users (blasters, applicators) & 47 & 2.3 & 0.4 & 4.4 & 0.23 & 0.03 & 0.36 \\
\hline 11 & Clean up squad & 25 & 6.9 & 1.9 & 7.8 & 0.27 & 0.05 & 0.33 \\
\hline 12 & Kiln demolition $\star$ & 3 & 10.0 & & & 0.62 & & \\
\hline
\end{tabular}

$\star$ One site only.

among users of sand, clean up squads, and kiln demolition workers, jobs which occur infrequently in the industry. Further details are given elsewhere. ${ }^{22}$

An ANOVA analysis of the logarithms of the data from the dust samples was carried out to identify the principal sources of variation in the data. The results for airborne concentrations of respirable dust showed highly significant systematic differences between occupational groups and between sites. A large part of the variation between sites was associated with kiln type: the sites operating Hoffman kilns were on average $50 \%$ dustier than other sites. After allowing for this difference, the remaining differences between sites were still highly significant. There was no evidence of systematic day to day or week to week variation. There was evidence of a significant interaction between sites and occupational groups: the ratios of average concentrations between occupational groups were not exactly the same at each site. However, the differences were small relative to the overall site and occupational group effects. Similar results were found for the quartz concentrations, except that the site to site variation in quartz was not associated with kiln type.

From these results, it was clear that the principal patterns in the occupational hygiene data could be summarised by a set of geometric means predicted by multiplying together the main effects of site and occupational group, as estimated from an ANOVA model containing only these terms. Geometric means predicted in this way for both dust and quartz concentrations were calculated, to be used as input to estimates of individual cumulative exposures. Jobs in earlier periods with the same kiln type were assigned current concentrations. At sites where a change of kiln type from Hoffman or intermittent to tunnel kilns had taken place, the concentrations for each occupational group were scaled up by a factor of 1.5 for the period while Hoffman and intermittent kilns were in use, and by 1.25 for the changeover period. Estimates of concentrations in jobs at sites not studied were based on the means for each occupational group over all tunnel kiln sites. To reflect the general but gradual move away from Hoffman and intermittent kilns, these were scaled up by 1.5 for the period before 1 July 1970, and 1.25 thereafter.

ESTIMATED EXPOSURES TO RESPIRABLE DUST AND QUARTZ

The set of estimated mean concentrations for the various sites, occupational groups, and periods was combined with individuals' work histories to estimate individual cumulative exposures to dust and to quartz, as described in the methods section. The figure summarises the distributions of the simple cumulative exposures to dust and quartz, in scatter plots which show their relations with age and with each other. These plots show clearly the very high estimated exposures for a few men who worked in kiln demolition, where the estimated concentrations were much higher than in other parts of the industry. Most of the estimated dust exposures were $<100 \mathrm{mg} . \mathrm{y} \cdot \mathrm{m}^{-3}$, and all but a few quartz exposures were $<10 \mathrm{mg} . \mathrm{y} \cdot \mathrm{m}^{-3}$.

For the rest, both dust and quartz exposures showed a range at each age, showing that any effects of age and of exposure will not be wholly confounded. The plot of quartz exposure against dust exposure (both on logarithmic scales) showed a close relation $(r=0.965)$, suggesting that it will be less easy to separate the effects of quartz from those of dust.

\section{MEDICAL SURVEYS}

Of the 1925 employees who attended these surveys and fulfilled the criteria for inclusion, 1852 were men and 73 were women. None of these women had any notable radiological abnormalities and were excluded from further analysis. At site 14 some participants chose not to have a chest radiograph taken because a chest $x$ ray service had visited the site six months earlier. Although it proved possible to obtain some of these films, 17 were not available. Another four films were excluded, two because one or more readers considered them to be unreadable, and two because of missing smoking or occupational history data. A final study group of 1831 men remained for analysis.

After these exclusions site 17 had the largest workforce (460) and site 4 the smallest (25). Age ranged uniformly from 16 to 65 , and the 

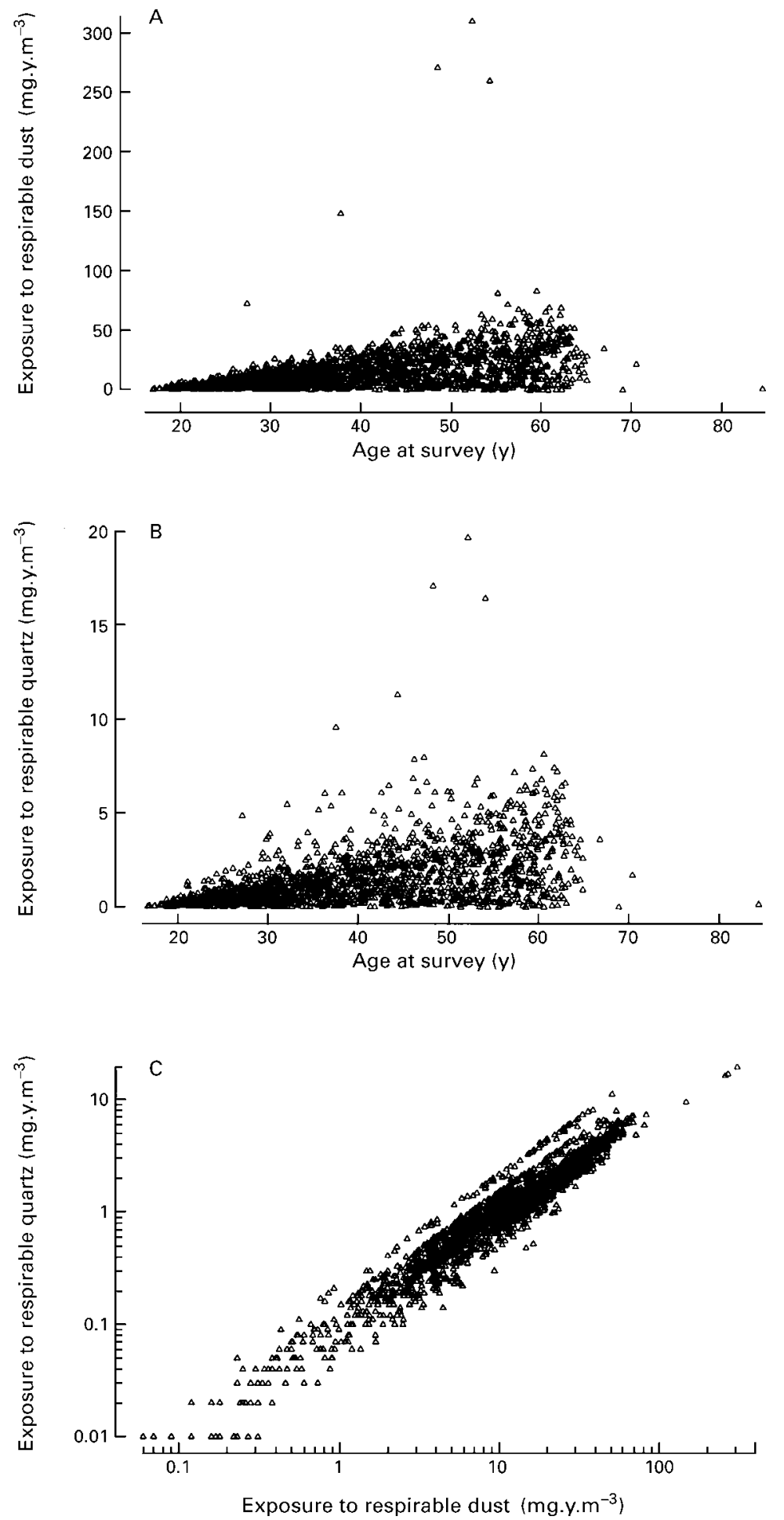

Pairwise scatter plots showing associations between men's estimated exposures to respirable dust and respirable quartz, and age at the survey. mean was 40 years for the study population. Of all male employees $42 \%$ were current smokers.

CHEST RADIOGRAPHY

Before the exclusion of those already referred to, 1912 valid radiographs were available for assessment by each reader. Readers 1,2 , and 3 classified $2.2 \%, 11.2 \%$, and $3.1 \%$ respectively as having any signs of small opacities (category $\geqslant 0 / 1$ ) whereas the same readers classified $0.8 \%, 2.8 \%$, and $2.5 \%$ films as having category $\geqslant 1 / 0$. The third reader produced the highest reading, category $3 / 2$ in one film, and also read the greatest proportion of films (1.6\%) above category $1 / 1$. These readings are summarised in table 3 , which also gives the median readings for small opacities.

Based on these median readings, $3.7 \%$ of films were classed as category $\geqslant 0 / 1$ and $1.4 \%$ as category $\geqslant 1 / 0$. Seven films were classified between $2 / 1$ and $2 / 3$, the highest median category recorded. All readers agreed on the presence of large opacities (category A) on only one film.

Table 4 shows the distribution of the men tabulated by age group and by cumulative quartz exposure. This table also shows the numbers of men in the same groups with radiographs classified as category $\geqslant 0 / 1$, and the observed prevalences ( $\%)$ of category $\geqslant 0 / 1$ in each group. Prevalence rose from zero at age $\leqslant 24$ to $8.5 \%$ for those aged $\geqslant 55$. Prevalence also increased from $1.0 \%$ among men exposed to $<0.5 \mathrm{mg} . \mathrm{y} \cdot \mathrm{m}^{-3}$ to $10.0 \%$ for those exposed to $\geqslant 4.0 \mathrm{mg} \cdot \mathrm{y} \cdot \mathrm{m}^{-3}$. However, a relation with exposure was only apparent in the oldest age group. A similar pattern was found for category $\geqslant 1 / 0$ but, because of the small numbers with this level of abnormality ( 25 men), the relations were less obvious. A similar relation was found with dust exposure (not shown).

The relation between radiographic abnormality and cumulative exposures to dust and quartz, in the presence of other factors, was examined by logistic regression. The results showed that the risk of having a category $\geqslant 0 / 1$ radiograph increased significantly with age and with exposure, and differed between sites even after allowance for exposure. Smoking effects suggested an increased risk in current smokers, but failed to reach the $5 \%$ level of significance. However, because risks of low level radiographic abnormalities are often found to be related to smoking, the smoking terms were retained in the model.

Models were fitted with dust and quartz exposures separately, and with both simultaneously. All of the exposure effect could be expressed in terms of the quartz exposures,

Table 3 Profusion of small opacities (n (\%)) on 1912 radiographs, by reader

\begin{tabular}{|c|c|c|c|c|c|c|c|c|c|c|}
\hline \multirow[b]{2}{*}{ Reader } & \multicolumn{9}{|c|}{ Profusion category on $x$ ray film } & \multirow[b]{2}{*}{ Total } \\
\hline & $0 / 0$ & $0 / 1$ & $1 / 0$ & $1 / 1$ & $1 / 2$ & $2 / 1$ & $2 / 2$ & $2 / 3$ & $3 / 2$ & \\
\hline 1 & $1869(97.8)$ & $26(1.4)$ & $8(0.4)$ & $4(0.2)$ & $2(0.1)$ & $1(0.0)$ & 0 & $1(0.0)$ & 0 & $1911^{\star}$ \\
\hline 2 & $1698(88.8)$ & $161(8.4)$ & $26(1.4)$ & $17(0.9)$ & $1(0.0)$ & 0 & $7(0.4)$ & $2(0.1)$ & 0 & 1912 \\
\hline 3 & $1852(96.9)$ & $11(0.6)$ & $13(0.7)$ & $7(0.4)$ & $6(0.3)$ & $12(0.7)$ & $9(0.5)$ & $1(0.0)$ & $1(0.0)$ & 1912 \\
\hline Mediant & $1764(96.3)$ & $42(2.3)$ & $9(0.5)$ & $8(0.4)$ & $1(0.1)$ & $2(0.1)$ & $4(0.2)$ & $1(0.1)$ & 0 & 1831 \\
\hline
\end{tabular}

*One film was considered to be unacceptable by this reader.

†Based on 1831 films after exclusion of all women and 10 others (see text for details). 
Table 4 Distribution of men in the study population, and $n(\%)$ with median profusion of small opacities category $\geqslant 0 / 1$ by age and cumulative exposure to respirable quartz

\begin{tabular}{|c|c|c|c|c|c|c|c|}
\hline & \multirow[b]{2}{*}{ Age at survey $(y)$} & \multicolumn{6}{|c|}{ Estimated cumulative exposure to respirable quartz $\left(m g \cdot y \cdot m^{-3}\right)$} \\
\hline & & $0.00-0.49$ & $0.50-0.99$ & $1.00-1.99$ & $2.00-3.99$ & $\geqslant 4.00$ & All \\
\hline \multirow[t]{6}{*}{$\operatorname{Men}(\mathrm{n})$} & $16-24$ & 158 & 47 & 8 & 0 & 0 & 213 \\
\hline & $25-34$ & 166 & 179 & 139 & 26 & 2 & 512 \\
\hline & $35-44$ & 79 & 90 & 153 & 109 & 14 & 445 \\
\hline & $45-54$ & 71 & 55 & 73 & 143 & 37 & 379 \\
\hline & $\geqslant 55$ & 34 & 23 & 62 & 96 & 67 & 282 \\
\hline & All & 508 & 394 & 435 & 374 & 120 & 1831 \\
\hline \multirow[t]{6}{*}{$\geqslant 0 / 1(n)$} & $16-24$ & 0 & 0 & 0 & - & - & 0 \\
\hline & $25-34$ & 1 & 2 & 2 & 0 & 0 & 5 \\
\hline & $35-44$ & 1 & 3 & 5 & 3 & 0 & 12 \\
\hline & $45-54$ & 2 & 5 & 2 & 16 & 1 & 26 \\
\hline & $\geqslant 55$ & 1 & 1 & 3 & 8 & 11 & 24 \\
\hline & All & 5 & 11 & 12 & 27 & 12 & 67 \\
\hline \multirow[t]{6}{*}{$\geqslant 0 / 1(\%)$} & $16-24$ & 0.0 & 0.0 & 0.0 & - & - & 0.0 \\
\hline & $25-34$ & 0.6 & 1.1 & 1.4 & 0.0 & 0.0 & 1.0 \\
\hline & $35-44$ & 1.3 & 3.3 & 3.3 & 2.8 & 0.0 & 2.7 \\
\hline & $45-54$ & 2.8 & 9.1 & 2.7 & 11.2 & 2.7 & 6.9 \\
\hline & $\geqslant 55$ & 2.9 & 4.3 & 4.8 & 8.3 & 16.4 & 8.5 \\
\hline & All & 1.0 & 2.8 & 2.8 & 7.2 & 10.0 & 3.7 \\
\hline
\end{tabular}

with no residual effect of dust. However, when dust was fitted first, the addition of quartz still gave a small (non-significant) improvement in the model. This was taken to suggest that the quartz was the more important fraction of the dust for risk of radiographic abnormalities, qualified by the caveats about the high correlation between the two exposures. There was no evidence of any influence on risk from work outside the heavy clay industry.

Models were fitted with the two alternative indices of time weighted exposure. None of these fitted better than the corresponding models with simple cumulative exposure, and

Table 5 Results of logistic regression of risk of median profusion of small opacities category $\geqslant 0 / 1$ (estimated baseline risk and odds are for a 25 year old non-smoker with a respirable quartz exposure of $\left.0.1 \mathrm{mg} \cdot y \cdot \mathrm{m}^{-3}\right)$

\begin{tabular}{|c|c|c|c|}
\hline \multirow{2}{*}{$\begin{array}{l}\text { Terms and factors estimated } \\
\text { Estimated baseline risk (\%) }\end{array}$} & \multirow{2}{*}{$\frac{\text { Estimate }}{0.62}$} & \multicolumn{2}{|c|}{$95 \% C I$} \\
\hline & & 0.12 & to 3.15 \\
\hline Equivalent baseline odds & 0.0063 & 0.0012 & to 0.0325 \\
\hline \multicolumn{4}{|l|}{ Multiplicative OR factors: } \\
\hline Cumulative quartz exposure (/doubling) & 1.33 & 1.05 & to 1.68 \\
\hline Age $(/ 10 y)$ & 1.75 & 1.32 & to 2.32 \\
\hline \multicolumn{4}{|l|}{ Smoking (relative to lifelong non-smoker) } \\
\hline \multicolumn{4}{|l|}{ Ex-smoker: } \\
\hline $1-10$ & 1.70 & 0.52 & to 5.59 \\
\hline $11-20$ & 1.75 & 0.72 & to 4.29 \\
\hline$\geqslant 21$ & 0.53 & 0.14 & to 1.97 \\
\hline \multicolumn{4}{|l|}{ Current smoker: } \\
\hline $1-10$ & 1.50 & 0.64 & to 3.52 \\
\hline $11-20$ & 2.28 & 1.07 & to 4.84 \\
\hline$\geqslant 21$ & 2.21 & 0.89 & to 5.47 \\
\hline \multicolumn{4}{|l|}{ Site (relative to site 1 ): } \\
\hline 2 & 0.38 & 0.04 & to 4.15 \\
\hline 3 & 0.33 & 0.05 & to 2.24 \\
\hline 5 & 2.51 & 0.51 & to 1.24 \\
\hline 6 & 0.24 & 0.02 & to 2.59 \\
\hline 11 & 0.20 & 0.02 & to 2.17 \\
\hline 12 & 0.11 & 0.02 & to 0.64 \\
\hline 15 & 1.36 & 0.22 & to 8.28 \\
\hline 16 & 0.50 & 0.09 & to 2.69 \\
\hline 17 & 0.89 & 0.23 & to 3.45 \\
\hline 18 & 1.03 & 0.21 & to 5.06 \\
\hline
\end{tabular}

Table 6 Predicted risks (95\% CI) of small opacities category $\geqslant 0 / 1$ for a non-smoker aged 55 at survey, and different combinations of intensity and duration of exposure

\begin{tabular}{llllll}
\hline & \multicolumn{2}{l}{ Quartz concentration $\left(\mathrm{mg} . \mathrm{m}^{-3}\right)$} & \\
\cline { 2 - 3 } $\begin{array}{l}\text { Exposure } \\
\text { duration }(y)\end{array}$ & 0.1 & & 0.4 \\
\cline { 2 - 3 } \cline { 5 - 6 } & Estimated OR & $95 \% \mathrm{CI}$ & & Estimated OR & $95 \%$ CI \\
\hline 10 & 4.3 & 2.4 to 7.5 & & 8.20 & 4.90 to 13.50 \\
20 & 6.0 & 3.6 to 9.8 & & 11.20 & 6.20 to 19.40 \\
30 & 7.2 & 4.3 to 11.7 & & 13.30 & 6.90 to 24.10 \\
40 & 8.2 & 4.9 to 13.5 & & 15.10 & 7.40 to 28.10 \\
\hline
\end{tabular}

the results are not shown here. None of the $\chi^{2}$ statistics indicated any serious lack of fit in the logistic regression models.

Table 5 summarises the relations between risk of category $\geqslant 0 / 1$ and age, smoking, site, and exposure to respirable quartz. The table shows a predicted baseline percentage risk, for a non-smoking man aged 25 years, with a respirable quartz exposure of $1 \mathrm{mg} \cdot \mathrm{y} \cdot \mathrm{m}^{-3}$ at site 1. This is also expressed converted to odds $(r /(100-r)$ where $r$ is the percentage risk). The remaining coefficients show the effects of smoking, age differences, site differences, and differences in exposure to quartz . These are expressed as odds ratios (ORs) - that is, factors which multiply the odds-with $95 \%$ cofidence intervals (95\% CIs) on these ratios.

Table 6 shows predicted prevalences from a similar logistic regression model, but excluding the term for site. These prevalences are thus averages over all sites. They represent the average predicted risks of category $0 / 1+$ for hypothetical 55 year old non-smokers with various patterns of cumulative quartz exposure.

Only 25 men had radiographs classified as category $\geqslant 1 / 0$ (table 3 ). Fitting logistic regresssion models based on distributing these among seven smoking groups and 18 sites was not considered useful.

The three radiographic film readers were not consistent in their classification of the shape of small opacities (rounded or irregular), the proportion of small opacities recorded as rounded ranging from $27 \%$ to $87 \%$. The seven men with category $2 / 1$ or greater had worked in the heavy clay industry for between 9 and 37 years and were aged 29-61 years. They worked at five different sites and had been employed in jobs as diverse as pan mill operator, brick setter, wicket erector, kiln burner, shovel driver, fork lift driver, and kiln demolition worker. Only two of them had worked for any time in other jobs constituting a potential respiratory hazard: in addition, the one man with category A large opacities had spent 35 years as a conveyor operator at quarries in the industry. Review of the abnormal chest radiographs (blind to status) by an experienced chest physician (CAS) indicated that the pattern of small 
opacities was not typical of other recognised occupational lung conditions-such as coalworkers' pneumoconiosis or classic silicosis and may represent a mixed dust type of pneumoconiosis.

\section{RESPIRATORY SYMPTOMS}

The analysis of respiratory symptoms was performed on 1852 men. The responses analysed were chronic bronchitis (persistent cough and phlegm), breathlessness (walking with others of the same age on level ground) and wheeze (attacks of wheezing or whistling in the chest at any time in the last 12 months). On average the prevalence of these symptoms was $14.2 \%$, $4.4 \%$, and $20.6 \%$ respectively.

These prevalences did not change significantly with age, although in those over 55 breathlessness occurred more often $(8.7 \%)$. As expected smoking had a strong effect on the presence of symptoms: $7.4 \%, 2.2 \%$, and $12.5 \%$ among never smokers rising to $22.5 \%$, $5.2 \%$, and $29.8 \%$ among current smokers for chronic bronchitis, breathlessness, and wheeze respectively.

Table 7 shows a slight increase in the prevalence of chronic bronchitis among the group of employees most exposed to dust. A stronger association for breathlessness is also apparent, largely accounted for by the greater age of the groups exposed to most dust. The prevalence of wheeze follows a similar pattern to that for chronic bronchitis.

With logistic regression analysis the odds ratios associated with the effect of a relatively high, $40 \mathrm{mg} . \mathrm{y} \cdot \mathrm{m}^{-3}$ increase in cumulative exposure to dust have been derived for prevalences of chronic bronchitis and breathlessness. Because of the significantly greater cumulative exposures to dust found among kiln demolition workers these men were considered separately.

There was a significant effect (at 5\% level, OR 1.5 (95\% CI 1.1 to 2.0$)$ ) of exposure to dust on the presence of chronic bronchitis for all heavy clay workers combined and for kiln demolition work alone (OR 1.6 (95\% CI 1.1 to 2.7)), having allowed for smoking, site, and time worked in other industries. Although the effect of exposure to dust in all jobs in the industry other than kiln demolition work was not significant, the data were consistent with a general effect of exposure to dust in the heavy clay industry. However, because of the small numbers and the relatively large 95\% CIs the results of the kiln demolition workers should be treated with caution.

For breathlessness, after adjusting for other factors, there was again a significant (at 5\%)

Table 7 Prevalence of chronic bronchitis, breathlessness and wheeze by cumulative exposure to dust $\left(\mathrm{mg} \cdot \mathrm{y} \cdot \mathrm{m}^{-3}\right)$ in 1851 men

\begin{tabular}{llclc}
\hline $\begin{array}{l}\text { Cumulative } \\
\text { exposure to } \\
\text { dust }\end{array}$ & $\begin{array}{l}\text { \% With } \\
\text { chronic } \\
\text { bronchitis }\end{array}$ & $\begin{array}{l}\text { \% With } \\
\text { breathlessness }\end{array}$ & $\begin{array}{l}\text { \% With } \\
\text { wheeze }\end{array}$ & Men n \\
\hline $0-4.9$ & 13.9 & 4.4 & 19.5 & 502 \\
$5-9.9$ & 13.4 & 2.9 & 20.7 & 381 \\
$10-19.9$ & 15.6 & 2.8 & 21.5 & 437 \\
$20-39.9$ & 12.8 & 5.8 & 18.6 & 413 \\
$\geqslant 40$ & 17.8 & 10.2 & 28.0 & 118 \\
All & 14.2 & 4.4 & 20.6 & 1851 \\
\hline
\end{tabular}

Table 8 Predicted risks of chronic bronchitis and breathlessness for a non-smoking 40 year old man with different exposure to dust in the heavy clay industry alone

\begin{tabular}{lll}
\hline & \multicolumn{2}{l}{ Risk \% } \\
\cline { 2 - 3 } $\begin{array}{l}\text { Dust exposure } \\
\left(\text { mg.y. } m^{-3}\right)\end{array}$ & Chronic bronchitis & Breathlessness \\
\hline 0 & 6.7 & 1.6 \\
20 & 7.2 & 2.0 \\
40 & 7.6 & 2.5 \\
80 & 14.0 & 3.3 \\
$160^{\star}$ & 26.0 & 6.6
\end{tabular}

${ }^{\star}$ Kiln demolition workers only.

effect of exposure to dust in general (OR 1.5 (95\% CI 1.1 to 2.2 )) and to dust in kiln demolition work separately (OR 1.5 (95\% CI 1.0 to 2.1)). The effect of exposure to dust in all jobs in the industry other than kiln demolition work was not significant, although the data were again consistent with a general effect of exposure to dust .

Predicted prevalences of chronic bronchitis and breathlessness relative to exposure to dust are shown in table 8 . For most workers in the industry the risk of these symptoms increasing in frequency with increasing exposure is slight. For example, a non-smoker, aged 40, with no exposure to dust would have a predicted prevalence of $6.7 \%$ increasing to $7.6 \%$ for 40 mg.y. $\mathrm{m}^{-3}$ exposure. However, the actual risks might be much greater or much smaller than those shown because of wide 95\% CIs (not shown).

\section{Discussion}

The average concentrations of respirable dust found in the occupational groups in this study are likely to be generally representative of the conditions at these and similar plants in the United Kingdom. These plants were mostly included on the basis of continuous operation for $\geqslant 20$ years, although two plants were commissioned on their present sites in 1974 . However, even at long running sites there have been changes to kiln type, fuel supply to kilns, and the introduction of local exhaust ventilation and respiratory protective equipment. We think that the change of kilns in some factories from the Hoffman or intermittent type of kiln to the tunnel type was the most important event to influence the history of exposure to dust for the workforce, and this has been taken into account when estimating history of exposure.

\section{DUST AND QUARTZ EXPOSURES}

Occasional high concentrations of dust recorded during the surveys were found in most occupational groups. The highest dust concentrations in six of these occupational groups occurred at one site (17) and the six other highest concentrations were found at five different sites, all of which were in the top third in order of overall dustiness.

Average dust concentrations in this study, which ranged from 0.5 to $2.5 \mathrm{mg} . \mathrm{m}^{-3}$ across 18 factories, were somewhat lower than the mean respirable concentrations of dust reported from five South African brickworks $\left(2.2 \mathrm{mg} . \mathrm{m}^{-3}\right)$ by Myers et al. ${ }^{9}$ A Dutch study ${ }^{22}$ reported 
respirable dust concentrations as high as 8.8 mg. $\mathrm{m}^{-3}$ and an estimated mean concentration of about $1.6 \mathrm{mg} \cdot \mathrm{m}^{-3}$ before any dust controls had been introduced. The general dust conditions in the British heavy clay industry seem to be no worse and if anything slightly better than those reported in other countries in the past few years. It should be noted that we did not include any very modern factories in our study, as we were interested in the health effects of long term exposure.

The gathering of so many dust samples from so many occupational groups and sites allowed the dust conditions in occupational groups at sites where measurements were not obtained to be estimated with a considerable degree of confidence. Furthermore, historical information about changes to type of kiln gave a reasonable basis for assigning dust and quartz concentrations to jobs at study and non-study sites in earlier years for the estimation of individual cumulative exposures to dust. The dustier conditions at sites operating the older, traditional Hoffmann kilns (higher by a factor of about 1.5) were clearly improved by the introduction of tunnel kilns, which was associated in many instances with other modernisations to the plant, especially in the packing areas.

Percentage quartz in the dust samples covered a similar range from job to job $(6 \%-20 \%)$ as from site to site $(5 \%-21 \%)$. These variations will depend on the feedstock and processes carried out at each plant. The range of percentage quartz found in this study could therefore be taken throughout the industry as representative of the content of respirable dust. This seems to be consistent with the $15 \%$ representative value reported for the Dutch brick industry ${ }^{23}$ but considerably higher than the $2 \%$ reported recently for South African brickworks. 9

Three per cent of all samples were found to have quartz concentrations above the United Kingdom MEL of $0.4 \mathrm{mg} . \mathrm{m}^{-3}$ : as many as $18 \%$ of samples at one site and two thirds of those in the pan mill area. Two thirds of the sites had at least one sample with a quartz concentration greater than the MEL, most of these being among pan mill workers, general labourers, sand users, clean up squads, and kiln demolition workers. The average quartz concentration of $0.11 \mathrm{mg} \cdot \mathrm{m}^{-3}$, based on measurements from all plants in this study, is greater than respirable quartz limits used in many other countries. For example, the upper limit of $0.1 \mathrm{mg} \cdot \mathrm{m}^{-3}$, used until recently in the United Kingdom, was exceeded in $33 \%$ of samples in the present study and on at least one occasion in all occupational groups, and at all sites. (In the United Kingdom the value of $0.1 \mathrm{mg} \cdot \mathrm{m}^{-3}$ was an occupational exposure standard, which is the concentration at which there is no indication of a risk to health, whereas the $0.4 \mathrm{mg} \cdot \mathrm{m}^{-3}$ limit represents a maximum exposure limit, an 8 hour time weighted average which should never be exceeded: however, a residual risk may exist.)

Mineralogical analysis of particles from three sites showed that free quartz particles were present in respirable airborne dusts. ${ }^{22}$ As the method used, scanning electronmicroscopy/ energy dispersive $x$ ray spectroscopy does not analyse thin layers of surface contamination, these results did not show that the quartz identified was any more or less hazardous than quartz found in other situations. Surface contamination has been shown to reduce the fibrogenicity of quartz, ${ }^{24}$ and from the sources of the minerals, it is reasonable to expect that the surfaces of quartz particles could be contaminated.

\section{RESPIRATORY HEALTH EFFECTS}

If less healthy men leave an industry preferentially, a study of only current workers may underestimate the frequency of ill health. The study population included good representation of all age groups, and the attendance rate indicated a good response. Given the generally low prevalence of respiratory disease in the current population and the lack of reports over the years of significant numbers of cases of pneumoconiosis arising from working in the heavy clay industry, the exclusion of leavers is unlikely to have seriously influenced qualitatively the estimates of health risks in the industry.

This study has generally confirmed the industry's expectations of a low frequency of radiological abnormality within the current workforce of the heavy clay industry. Although radiographic surveys of brick and tile works have been carried out by several companies in the United Kingdom, there have been no published reports on the presence of radiographic abnormalities of employees in the United Kingdom since the study of Keatinge and Potter in $1949 .{ }^{8}$ They found only two men out of 73 with any degree of such abnormality (minimal changes only)

The prevalence of pneumoconiosis in the present study $(1.4 \%$ with category $\geqslant 1 / 0)$ tends towards the lower end of the range of published values and is considerably lower than the $4 \%$ prevalence (category $\geqslant 1 / 0$ ) reported among 268 black brickworkers in South Africa. ${ }^{14}$ However, in the South African study, 176 men were excluded who had spent $\geqslant 2$ years exposed to "siliceous dusty conditions". Although their prevalence figure is likely to be an underestimate for the workforce as a whole, an earlier South African study ${ }^{13}$ of stock brick workers identified an incidence of $4.3 \%$. In the United States $5 \%$ of brickworkers had abnormal radiographs although exact categories were not reported. ${ }^{12}$

It is of considerable concern that a 29 year old man who had worked in the heavy clay industry for 13 years in post-production areas, should have the highest level of radiological abnormality (median category 2/3) found in this study. Note that the ILO classification is descriptive, not diagnostic, and we do not have information on the subsequent course of his condition, nor on the results of any diagnostic procedures. Small opacities of category 1 , which represent definite but slight abnormality, can be the result of age, smoking, or other disease, as well as pneumoconiosis, but the relations with exposure to dust confirm that they include cases of pneumoconiosis. These results show that, although pneumoconiosis does occasionally occur, employees 
of the heavy clay industry may not be at high risk of the disease.

Small radiographic opacities in the chest radiograph can represent areas of fibrosis, emphysema, or inflammation on aggregates of dust. The association with exposure to quartz in this population suggests that fibrosis and inflammation are the most likely dust related pathology - namely, silicosis - conceivably modified by the accompanying clay minerals.

Our results suggest that there are relatively few people with significant clinical abnormality among the current workforce. However, because of the cross sectional nature of this study information on leavers would be useful to strengthen our confidence that this finding is not biased by preferential departure of employees with such abnormalities.

Our analysis predicts that $1.4 \%$ of nonsmokers aged 40 exposed to an average dust concentration of $2.5 \mathrm{mg} \cdot \mathrm{m}^{-3}$ for 20 years would be expected to have category $\geqslant 1 / 0$ compared with $0.6 \%$ of those exposed to the lowest dust concentration. In comparison there is a $2.8 \%$ probability that a coalminer would have simple pneumoconiosis of category $\geqslant 1$ after 20 years of exposure to coalmine dust of medium rank at an average concentration of $2.5 \mathrm{mg} \cdot \mathrm{m}^{-3}$, equivalent to an exposure of $50 \mathrm{mg} \cdot \mathrm{y} \cdot \mathrm{m}^{-3} .{ }^{25}$ Given the high quartz concentrations experienced by a considerable proportion of the workforce in the heavy clay industry, this relatively low prevalence might be considered to be surprising. However, the presence of clay minerals, and specifically the release of aluminium or other ions, on the surface of well weathered particles containing quartz, is thought to reduce the toxicity of inhaled quartz. ${ }^{26}$ Illite seems to be a particularly effective mineral in this respect, whereas kaolin is less so. Nevertheless, the estimated exposureresponse relation for quartz suggests considerable risks of radiological abnormality even at concentrations of $0.1 \mathrm{mg} . \mathrm{m}^{-3}$ of quartz. More detailed analysis of the risks at low exposures might be advisable.

Of this study population $14 \%$ had chronic bronchitis, a higher proportion than is found among workers not exposed to dust-for example, 9\% among postmen (Soutar et al). ${ }^{27}$ By contrast only $7 \%$ of South African brickworkers were reported to have chronic bronchitis, ${ }^{28}$ although the definition of this condition was not clear.

Breathlessness was less often reported by this workforce, $4 \%$ on average, than by South African brickworkers $(9 \%),{ }^{28}$ although again the definition of this symptom is not entirely clear. Nevertheless this symptom is occupationally related, both to dust in general and to dust from kiln demolition work separately.

The exposure-response relation for chronic bronchitis in this population is not strong but given a consistency in the general relation, the small group of kiln demolition workers showed a particularly severe effect. Dust exposures of $>100 \mathrm{mg} \cdot \mathrm{y} \cdot \mathrm{m}^{-3}$ (10 mg. $\mathrm{m}^{-3}$ for 10 years) should not be unexpected in this group, which is potentially exposed to a considerable risk of chronic bronchitis (and pneumoconiosis, if this exposure were to be sustained).
Although our analysis has identified a relation between radiological change and exposure to dust containing quartz, the study provides limited information as to whether this is more closely associated with respirable dust as a whole or with the quartz content in particular, because of the very high correlation between the two exposure indices. The quartz content is more likely to have caused radiological change, both initially and according to the evidence from logistic regression analysis.

The results of the present study indicate that health surveillance should be carried out on those regularly exposed to heavy clay dust, containing concentrations of quartz $>0.1$ $\mathrm{mg} \cdot \mathrm{m}^{-3}$. This need not be as frequent as the 2 years currently recommended in the United Kingdom for other workers exposed to silica, owing to the relatively low risks to respiratory health found in this study. With the information presented here (tables 6 and 8) it should be possible to establish control standards for dust and quartz to safeguard the health of the workforce in this industry. Furthermore, because the occasional high concentrations of quartz tended to be found in a few well recognised activities (kiln demolition, clean up squad, and sand users), dust control should be relatively straightforward by means of changes to the way the job is carried out, enclosure of dusty processes or use of respiratory protection, as appropriate.

We thank the National Federation of Clay Industries (now British Ceramics Confederation) and the Health and Safety Executive for financial support; Drs J Bennett, MA Rickards, and PO Pern for reading chest radiographs, Dr BG Miller and many other colleagues from the Institute of Occupational many other colleagues from the Institute of
Medicine too numerous to mention individually.

1 American Conference of Governmental Industrial Hygienists. Silica, crystalline-quartz. In: ACGIH. Documentation of the threshold limit values and biological exposure indices for

2 Health and Safety Executive. Crystalline silica. London: The Stationery Office, 1992. (Guidance note EH59.)

3 World Health Organisation. Recommended health-based limits in occupational exposure to selected mineral dusts (silica coal). Geneva: WHO, 1986. (WHO technical report series 734.)

4 Walton WH, Dodgson J, Hadden GG, et al. The effect of quartz and other non-coal dusts in coalworkers' pneumoconiosis. Part 1. Epidemiological studies. In: Walton WH, ed. Inhaled particles IV (in two parts). Proceedings of an International Symposium organised by the British Occupational Hygiene Society. Edinburgh: BOHS, 22-6 September 1975; 2:669-90.

5 Rajhans GS, Budlovsky MD. Dust conditions in brick plants of Ontario. Am Ind Hyg Assoc $\mathcal{F}$ 1972;33:258-68.

6 Trice MF. Health of brick and tile plant workers in North Carolina. Bulletin of the American Ceramics Society 1941;20: 130-4.

7 Keppler JF, Bumsted HE. A dust study of the building brick industry in Indiana. Archives of Industrial Hygiene and Occupational Medicine 1950;2:735-41.

8 Keatinge GF, Potter NM. Health and environmental conditions in brickworks. Br F Ind Med 1949;1:31-44.

tions in brickworks. Br F Ind Med 1949;1:31-44.
9 Myers JE, Lewis P, Hofmeyr W. Respiratory health of brickworkers in Cape Town, South Africa. Background, aims and dust exposure determinations. Scand $\mathcal{F}$ Work Environ Health 1989a;15:180-7.

10 Sayers RR, Dalla Valle JM, Bloomfield SG. Occupational and environmental analysis of the cement, clay, and pottery industries. Washington, DC: US Treasury Department 1937. (Public Health Bulletin No 238.)

11 Wiecek E, Goscicki J, Indulski J, et al. Exposure to dust and occupational diseases in building ceramics plants (brickyards). Medycyna Pracy 1983;34:35-45.

12 Palmer A, Donaldson HM, Anderson LJ, et al. North Carolina brick industry: industrial hygiene and respiratory disease for Occupational Safety and Health, 1980 .

13 Sluis-Cremer GK. Pneumoconiosis in South Africa. S Afr Med f 1972;46:322-4.

14 Myers JE, Garisch D, Louw SJ. Respiratory health of brickworkers in Cape Town, South Africa. Radiographic abnor malities. Scand F of Work Environ Health 1989;15:195-7. 
15 Health and Safety Executive. General methods for the gravimetric determination of respirable and total inhalable dust. tive, 1989 .

16 Health and Safety Executive. Quartz in respirable airborne dusts. Laboratory method using infra-red spectroscopy (direct method). (MDHS 37). London: The Stationery Office, 1987.

17 Health and Safety Executive. Quartz in respirable airborne dusts. Laboratory method using $x$ ray diffraction (direct method). (MDHS 51/2). London: The Stationery Office, 1988.

18 Health and Safety Executive. Quartz in respirable airborne dusts. Laboratory method using infra-red spectroscopy ( $\mathrm{KBr}$ disc technique). (MDHS 38). London: Health and Safety Executive, 1984 .

19 International Labour Office. Guidelines for the use of ILO international classification of radiographs of pneumoconiosis. Geneva: ILO, 1980. (Occupational Safety and Health Series, No 22 (Rev 80).)

20 Medical Research Council. Ouestionnaire on respiratory symptoms. London: Medical Research Council, 1986.

21 Hosmer DW, Lemeshow S. Applied logistic regression. New York: Wiley, 1989.

22 Love RG, Waclawski ER, Maclaren WM, et al. Crosssectional study of risks of respiratory disease in relation to expo- sures of airborne quartz in the heavy clay industry. Edinburgh: Institute of Occupational Medicine, 1994. (IOM Report $\mathrm{TM} / 94 / 07$.)

23 Buringh E, Van der Belt R, Van der Wal JF. Dust control measures in Dutch brickworks. Ann Occup Hyg 1990;34: 483-97.

24 Le Bouffant L, Daniel H, Martin JC. Quartz as a causative factor in pneumoconiotic lesions in coalminers. Luxembourg: Commission of the European Communities, 1977. (Industrial Health and Medicine Series no 19.)

25 Hurley JF, Maclaren WM. Dust-related risk of radiological changes in coalminers over a 40 year working life: report on work commissioned by the National Institute for Occupational Safety and Health. Edinburgh: Institute of Occupational Medicine, 1987. (IOM Report TM/87/09.)

26 Le Bouffant L, Daniel H, Martin JC, et al. Effect of impurities and associated minerals on quartz toxicity. In: Walton WH, ed. Inhaled particles V. Oxford: Pergamon, 1982:625-34.

27 Soutar CA, Campbell SJ, Gurr DC, et al. Cross-sectional studies of respiratory disease in British coalminers. Edinburgh: Institute of Occupational Medicine, 1989. (IOM Report TM/88/06.)

28 Myers JE, Cornell JE. Respiratory health of brickworkers in Cape Town, South Africa. Symptoms, signs and pulmonary function abnormalities. Scand $\mathcal{F}$ Work Environ Health 1989;15:188-94.

\section{Vancouver style}

All manuscripts submitted to Occup Environ Med should conform to the uniform requirements for manuscripts submitted to biomedical journals (known as the Vancouver style.)

Occup Environ Med, together with many other international biomedical journals, has agreed to accept articles prepared in accordance with the Vancouver style. The style (described in full in the $\mathcal{F} A M A[1]$ ) is intended to standardise requirements for authors, and is the same as in this issue.

References should be numbered consecutively in the order in which they are first mentioned in the text by Arabic numerals on the line in square brackets on each occasion the reference is cited (Manson[1] confirmed other reports[2][3][4][5]). In future references to papers submitted to Occup Environ Med should include: the names of all authors if there are three or less or, if there are more, the first three followed by et al; the title of journal articles or book chapters; the titles of journals abbreviated according to the style of Index Medicus; and the first and final page numbers of the article or chapter. Titles not in Index Medicus should be given in full.

Examples of common forms of references are:

1 International Committee of Medical Journal Editors. Uniform requirements for manuscripts submitted to biomed journals. $7 A M A$ 1993;269:2282-6.

2 Soter NA, Wasserman SI, Austen KF. Cold urticaria: release into the circulation of histmaine and eosinophil chemotactic factor of anaphylaxis during cold challenge. N Engl F Med 1976;294:687-90.

3 Weinstein L, Swartz MN. Pathogenic properties of invading micro-organisms. In: Sodeman WA Jr, Sodeman WA, eds. Pathologic physiology, mechanisms of disease. Philadeleds. Pathologic physiology, mechanism
phia: W B Saunders, 1974:457-72. 